\title{
The Ontological Importance of Being a Perceptual Attitude
}

\author{
Sebastián Sanhueza Rodríguez*
}

Received: 30 October 2018 / Accepted: 17 April 2019

\begin{abstract}
Current philosophical debates about perception have largely ignored questions concerning the ontological structure of perceptual experience, so as to focus on its intentional and phenomenological character. To illustrate and put pressure on this tendency, I revisit the controversy between doxastic views of perception and Gareth Evans's objection from over-intellectualization. I suggest that classic versions of the doxastic view are to a good extent driven by an ontological characterization of perceptual attitudes as nonfactive states or dispositions, not by a cognitively complex picture of perceptual content. Conceived along these lines, the doxastic view unveils an ontologically significant story of perceptual experience for at least two reasons: on the one hand, that characterization avoids the line of reasoning leading up to sense-datum theories of perception; and, on the other, it bears on recent discussions about the temporal structure of perceptual experience. Although I do not endorse the doxastic view, my goal is to highlight the importance of the relatively neglected ontological motivations thus driving that kind of account.
\end{abstract}

Keywords: Nonfactivity; perceptual attitudes; processes; relationalism; representationalism; states.

* Catholic University of Maule

Faculty of Religious and Philosophical Studies and The Neuropsychology and Cognitive Neurosciences Research Center, Catholic University of Maule, Avenida San Miguel 3605, Talca, Maule Region, Chile

$\triangle$ ssanhue@gmail.com

(c) The Author. Journal compilation (C) The Editorial Board, Organon F.

This article is distributed under the terms of the Creative Commons Attribution-NonCommercial 4.0 International Public License (CC BY-NC 4.0). 
In philosophical debates, opposing sides may talk past each other in spite of apparently sharing a common set of notions and concerns. Although these misunderstandings may have to do with the specific meaning of key terms and claims, they often relate to background assumptions the full import of which even the very participants of the relevant discussion fail to grasp. By making such assumptions explicit, it is not only possible to trace the source of the relevant misunderstanding, but also to get a better grip on what is at stake in the relevant debate and how it could move forward into the future. This piece aims precisely to bring out such conflicting assumptions at the basis of current debates in the philosophy of perception. In broad lines, the thought may be expressed as follows: while an important tradition of philosophical discussion - in particular, the protracted and ever increasingly more complex debate between relationalism and representationalism - has by and large focused on accounting for the intentionality and the phenomenology of perception, a neglected but significant stream has instead been driven by considerations concerning the ontological structure of our perceptual experiences. This contrast does not imply that two detached lines of discussions cut across the philosophy of perception, but that one and the same landscape of philosophical views may be approached from two different but potentially complementary perspectives: one concerned with what and how experience (re)presents the world to us, and another one concerned with what kinds of items perceptual experiences actually are. The general goal of this piece is to highlight the existence of both kinds of approaches - in particular, the existence and the importance of the comparatively neglected ontological approach to the study of perception.

To focus this task, I shall build on a well-known controversy in recent philosophical history, namely, that between doxastic views of perception and Gareth Evans's objection from over-intellectualization. I shall argue that classic versions of the doxastic view do not, as it is commonly thought, fall under the scope of Evans's target, and that this is so because the relevant players shared different background assumptions. Evans was mainly concerned with understanding how the contents of perception may ground the ways in which we think and talk about the objective world: understandably, he takes doxastic views to provide cognitively or conceptually complex accounts of perceptual content. However, still under the strong influence of 
Rylean and Wittgensteinian conceptual analysis, doxastic views may actually be read as striving to deliver an account of perceptual attitudes as nonfactive states or dispositions. In other words, the comparison between perception and belief picks up on the mental attitudes rather than the contents of the relevant perceptual and doxastic phenomena. Thus understood, doxastic views are not only capable of fulfilling the kind of job they were originally intended to fulfill, namely, that of providing a respectable alternative to theories widely unpopular for their ontological commitment to private objects of perception. They also provide a crucial historical bridge between the mid-Twentieth Century's philosophical and linguistic contributions to our understanding of psychological concepts and recent ontological work on the temporal structure of mental phenomena.

To remain absolutely clear about the scope of this piece. While it is relatively clear that I take distance from Evans's objection, I am not about to defend doxastic theories of perception here - evidence of which, as explained later on, is that a characterization of perceptual attitudes as nonfactive states also fits non-doxastic views of perception, e.g. recent versions of representationalism. My point is that there are important ontological considerations - not only intentional and phenomenological ones, as it is usually assumed - underpinning philosophical reflection about how perceptual experiences should be individuated. The specific controversy I revisit here is thereby intended to illustrate my general goal.

This piece will proceed in five stages. First, I sketch how doxastic views of perception - in particular, D.M. Armstrong's and George Pitcher's classic versions - and Evans's objection are traditionally taken to clash on the notion of perceptual content. Secondly, I explain why Evans's objection misses its intended targets: in a nutshell, the relevant doxastic views rely on notions of belief and concept far too undemanding to over-intellectualize perception. Thirdly, to begin unpacking the ontological import of doxastic views, I explain how their underpinning characterization of perceptual attitudes as nonfactive strives to meet the threat posed by sense-datum theories. Fourthly, I relate a stative characterization of perceptual attitudes to classic as well as fresh discussions concerning the temporal or otherwise ontological categorization of experience. Finally, I wrap things up and briefly refer to the relationship between the ontological picture here developed and 
the most popular views of perception nowadays-i.e. representationalism and relationalism.

\section{Doxastic views and over-intellectualization}

Recent philosophy of perception has mainly addressed questions about intentional objects and contents - that is, about the worldly items which perceptual experiences present to us and the ways in which such items are thereby presented. By contrast, relatively little systematic attention has been devoted to the nature of the experiential attitudes which thus open the world to us. ${ }^{1}$ Doxastic or belief accounts of perception classically hold that perceiving consists in acquiring - or being disposed to acquire-beliefs about the perceivable environment. Bearing the previous distinction between experiential objects/contents and experiential attitudes in mind, it is natural to read those views as making a controversial claim about the cognitive complexity of perceptual content: perceiving consists in the acquisition of perceptual information that is conceptually structured; or, relatedly, perceptual experiences are perceptual beliefs, that is, mental phenomena which accurately or inaccurately represent the world in a conceptual or otherwise propositional way. As previously mentioned, however, I believe that doxastic views reveal a deeper ontological characterization of experiential attitudes in terms of nonfactivity and stativity. This characterization aims to illustrate a more general point: an account of perception may be philosophically relevant not only for specifying the objects or contents of experience, but also for describing what kinds of psychological attitudes thereby (re)present the world to us.

Flourishing in the late ' 60 s and the early '70s, doxastic views of perception are materialist alternatives to the then increasingly unpopular sensedatum theories. Armstrong, for instance, held that "perception is nothing

1 Something along the lines of the present distinction between object/content and attitude features in Tim Crane's work (cf. Crane, 2001, 2003). For the notions of intentional object and intentional content, cf. (Crane 2001; 29, 31). What I term experiential attitude roughly corresponds to what Crane calls intentional mode (cf. Crane 2001, 31-32). 
but the acquiring of true or false beliefs concerning the current state of the organism's body and environment. [...] Veridical perception is the acquiring of true beliefs, sensory illusion the acquiring of false beliefs' (Armstrong 1968, 209). Again, Pitcher claimed that 'sense perception is the acquiring of true beliefs concerning particular facts about one's environment, by means of or by the use of, one's sense organs' (Pitcher 1971, 65), Like current representationalists and relationalists, both writers invoke the notion of belief to throw light on the phenomenon of perception and its relation to hallucinatory and other cognitive phenomena downstream perception. Doxastic views are not as unpopular as it might seem (e.g. Roxbee Cox 1971; Sibley 1971; Craig 1976; Heil 1984; Byrne 2009; Glüer 2009, 2018; among others). But, for present purposes, I shall focus here on Armstrong's and Pitcher's classic portrayals: for, given that their proposals represent two of the purest versions of the doxastic stance, one might assume that, with the appropriate qualifications in place, what holds for them may also hold for other, more nuanced versions.

To the extent that it emerges in order to resist sense-datum theories of perception, a key motivation of the doxastic view is ontological. Sense-datum theories held that perceptual phenomena should be conceived as psychological relations of awareness between a subject and the objects of perception, where the relevant objects were not items of the publicly accessible world, but mind-dependent, private ones that roughly matched the array of so-called secondary properties (e.g. colours, sounds, etc.). One (but by no means the only) way of motivating the introduction of such mind-dependent items - also known as sense-data - consists in comparing normal or veridical cases of perceptual experience with anomalous ones, e.g. illusions and hallucinations. While common cases of perception naturally lead us to think that we are aware of the mind-independent, medium-sized world, illusory and hallucinatory phenomena indicate that we could be aware of perceivable properties or objects which fail to exist in our ordinary objective reality. By stressing the introspective or otherwise subjective similarities between both kinds of experiences, the sense-datum theorist accounts for both experiential categories in a similar way: whether normal or anomalous, experiences are conceived as psychological relations of awareness between subjects and mind-dependent, private items. 
Doxastic views of perception thus emerge as an attempt to account for perceptual phenomena without committing to the existence of private, mind-dependent objects of perception - a point I shall return to in section 3. For the time being, it is important to stress that these accounts are often read as stating that perception is belief, as opposed to merely claiming that perception is like belief. Against this interpretative backdrop, they are also taken to make a controversial claim about perceptual content. Armstrong and Pitcher would allegedly suggest that perceptual experiences represent the perceivable environment in a way similar to that in which beliefs do so: in other words, they would assimilate the contents of perceptual experience to those of belief. This reading is crystalized in Evans's objection from overintellectualization. ${ }^{2}$ According to it, having beliefs is an affair more cognitively sophisticated than having perceptual experiences: for, on the face of it, the way we or lower-level animals perceive the world, need not be anything as sophisticated as the way in which cognitive states such as beliefs represent it. Since perception is an operation of a relatively primitive informational system, its respective account should avoid relying on more sophisticated cognitive terms. Thus, Evans feels that explaining perception in terms of belief 'gets things the wrong way round. It is as well to reserve 'belief' for the notion of a far more sophisticated cognitive state: one that is connected with (and, in my opinion, defined in terms of) the notion of judgement, and so, also, connected with the notion of reasons. The operations of the informational system are more primitive' (Evans 1982, 124; also cf. McDowell 1994, 60)

So, the objection seems to run as follows: notions like belief and judgement are closely related to the possibility of ascribing concepts to the relevant cognitive subjects; but conditions of concept-possession intuitively seem to be more stringent than those of experience-ownership - after all, we are ready to identify perceiving organisms (e.g. newborn babies, dogs, bats, etc.) that fail to qualify as subjects of propositional attitudes in the traditional sense of the expression; hence, it seems intuitively misplaced to characterize experiences in terms of concept-dependent states like beliefs. Although it is by no means obvious in what sense the conditions of concept-

2 The force of Evans's objection is still felt in recent philosophical work, e.g. (Heck Jr 2000; Martin 2002; Johnston 2006). 
or belief-possession are more cognitively demanding than those of experience-possession, it is clear that the objection may be read as targeting the way in which the doxastic view models the contents of perceptual experience. ${ }^{3}$ Thus understood, the worry seems to be that characterizing how our senses deliver information to us as concept-dependent misdescribes the cognitive sophistication of perceptual experiences vis-à-vis beliefs. After all, the realm of items which a subject could experience and the way in which she could experience them, could surely transcend the conceptual repertoire she is endowed with.

To sum up, I have outlined here a widely spread understanding of the dialectic between classic doxastic views of perception and Evans's objection from over-intellectualization. As initially mentioned, my ultimate goal is neither to neutralize the force of Evans's objection nor to vindicate a doxastic view. This local controversy is intended to illustrate how philosophical thinking about perceptual experiences need not draw on considerations from intentionality and phenomenology alone, but also on claims concerning the ontological structure of perceptual attitudes in particular or perceptual experiences in general. While I do not endorse a doxastic view, it is important to appreciate its sensitivity to the ontological import of perceptual attitudes, at least to the extent that such an ontological import bears on our understanding of how experiences are individuated.

3 Evans's objection may also be read in a different way: instead of targeting a particular understanding of perceptual content, it could criticize the assimilation of perceptual attitudes to doxastic ones, and it would do so because both kinds of attitudes are functionally different - for example, doxastic attitudes are, unlike perceptual ones, susceptible of rational assessment. However, I shall ignore this alternative reading for two reasons. First, it is by no means straightforward to me how one could account for the conceptual character of belief-attitudes without referring to features, conceptual or otherwise, of belief-contents. Secondly, this alternative reading would not, I think, affect the local exegetical claim I shall make here, which is this: the objection from over-intellectualization does not undermine classic doxastic theories of perception, for the latter do not strive to model perceptual experiences in terms of conceptual structure - at least as normally understood - but in terms of the features of nonfactivity and stativity. 


\section{Undemanding perceptual concepts and beliefs}

Now I move on to show that doxastic theories of perception need not clash with the objection from over-intellectualization, for they need not deliver a story about the conceptual or otherwise cognitive structure of perceptual content, but one about how perceptual attitudes - and, as such, perceptual experiences in general - should be ontologically categorized. In this section, I show that classic doxastic theories did not take issue with an intuitive understanding of the cognitive relationship between perception and belief: since writers like Armstrong and Pitcher invoke notions of belief and of concept that are far too rudimentary to over-intellectualize the contents of perceptual experience, their take on perception does not result in a cognitively demanding depiction of experiential contents. This will set the stage for the next two sections, where I suggest that doxastic views might be ontologically significant for specifying key features of experiential attitudes: a bit more specifically, the suggestion will be that the point of comparing perception and belief may be to outline an understanding of perceptual attitudes as nonfactive states. ${ }^{4}$

Do Armstrong and Pitcher over-intellectualize perception, then? They undeniably use the term 'belief' in order to clarify the notion of perceptual experience. Again, they acknowledge the intimate link between the notions of belief and concept (cf. Armstrong 1968, 210; Pitcher 1971, 94). But whether they invoke words like 'belief' and 'concept' or not is only a terminological issue. The crucial point is whether Armstrong and Pitcher wield such terms in a cognitively loaded way. I do not think they did. Doxastic theorists were fully aware of, and provided for, the worry at the heart of the objection from over-intellectualization. Armstrong, for example, notes that the "word "belief" is a stumbling-block. To talk of beliefs may seem to be to talk in a very sophisticated and self-conscious way, quite unsuited to

4 A terminological note. I do not use the noun "stativity" to refer to the feature in virtue of which certain mental attitudes state or assert how things are, but to refer to an ontological understanding of the members of a given (physical or psychological) category as states - that is, as opposed to, say, processes or instantaneous events. I shall say a bit more about the distinction between states, processes, and instantaneous events later on. 
such an unsophisticated thing as perception' (Armstrong 1968, 209). As I shall presently explain, both his and Pitcher's accounts tried to address the relevant worry. For the time being, it is worth bearing in mind that Armstrong continues using that word because he takes it to be less inappropriate than other terms (cf. Armstrong 1968, 209-10).

Armstrong draws a distinction between perceiving, perceptual experience proper, and perceptual belief. The first two notions are relatively straightforward: while perceiving stands for the acquisition of environmental information, perceptual experiences are states of introspective awareness by means of which perceivers track the relevant informational flow (cf. Armstrong 1968, 214-15, 226). The notion of perceptual belief is trickier. At times, it naturally picks up on perceptual attitudes: then, the notion seems to overlap with the previous idea of perceptual experience. But Armstrong also wants to fix a special use in which perceptual beliefs simply stand for the environmental information that the previous attitudes convey to the perceiver (cf. Armstrong 1968, 210). Thus understood, the notion picks up on information included within the content of experiences. This is, I believe, the use Armstrong more frequently relies on when claiming that perceptual beliefs are sub-verbal or fail to presuppose linguistic abilities: 'since perception can occur in the total absence of the ability to speak, we are committed to the view that there can be concepts that involve no linguistic ability' (Armstrong 1968, 210). Or again, when he holds that the conditions of concept-possession underpinning the relevant beliefs are less demanding than Evans would allow. Armstrong would, for example, ascribe colour-concepts to a baby capable of being systematically responsive to blocks of different colours (cf. Armstrong 1968, 246; also cf. Smith and Jones 1986, 104). According to him, a subject possesses a concept $\mathrm{C}$ if she is capable of systematically distinguishing worldly items that instantiate $\mathrm{C}$ from those that fail to do so. Since acts of perceptual discrimination count as forms of behaviour, he is prepared to ascribe $\mathrm{C}$ to an organism if the latter is capable of discriminating items which instantiate, say, the property or the relation that falls under $\mathrm{C}$ from items which fail to do so. And while this constraint on concept-possession is not trivial, it is relatively undemanding: it allows for concept-ascriptions (say, to babies or other primitive creatures) which other theories of concept would forbid. Armstrong thereby takes himself to 
describe features of experiential contents: accordingly, he would reject the charge of modeling the contents of experience in a cognitively heavy-duty way; according to him, perceptual phenomena simply involve the acquisition of sub-verbal information that endowed perceivers with capacities of discriminatory behaviour.

Specific and terminological differences aside, Pitcher also strived to circumvent the threat of over-intellectualization, and he did so with the help of a distinction between conscious and unconscious beliefs. Although it is controversial to classify beliefs either as conscious or as unconscious (cf. Crane 2001), all Pitcher aims to do here is to draw a line between mental states that differ in cognitive sophistication. Thus, conscious beliefs are states we usually associate to conceptually sophisticated tasks, such as those 'of entertaining propositions and assenting to them, of making (conscious) judgments, or anything of that sort' (Pitcher 1971, 71). By contrast, having unconscious beliefs does not involve entertaining and assenting to propositions, or judging: 'to have a belief of this kind is to have a complex disposition to act (or behave) in certain ways under certain specifiable conditions' (Pitcher 1971, 71). Like Armstrong, Pitcher aims to keep his notion of perceptual belief apart from sophisticated cognitive connotations. To pull this off, he characterizes perceptual experiences as unconscious beliefs. The foregoing remarks, I think, suggest that Armstrong as well as Pitcher strived to model the controversial notions underpinning their theories of perception in ways that avoided the problem of over-intellectualization.

Since Armstrong and Pitcher do not take perceptual beliefs to stand for cognitively sophisticated states - quite the opposite, they made efforts to deny that that is the case - their accounts are not targeted by Evans's objection. The former's views and the latter's critique talk past each other insofar as they trade in terms of different notions of concept and belief. What Armstrong and Pitcher have in mind is a relatively rudimentary notion of concept as a discriminatory capacity that human adults, babies, and even certain lower-level creatures (e.g. cats and dogs) possess: on that basis, they build their perceptual beliefs as cognitively rudimentary attitudes in virtue of which subjects are sensitive to certain kinds of environmental information. Evans, meanwhile, grounds his understanding of beliefs on the notion of concepts which we know and love - that is, those abstract items 
which set fully developed adults apart from babies and snails. Armstrong's and Pitcher's beliefs need not relate to the notions of judgement and of reasons; those of Evans's have to. In vernacular philosophical language, we should perhaps say that Armstrong and Pitcher are not talking about beliefs, but about a structurally similar albeit still different kind of dispositional state. This is the reason why the objection from over-intellectualization does not target the relevant doxastic accounts of perception. ${ }^{5}$

But if a doxastic account need not model perceptual experiences as cognitively sophisticated attitudes, why do they expose themselves to potential confusion by using the word "belief"? This concern actually gestures at two different questions: (i) if the concept that doxastic theories express by means of the word "belief" is so broad that does not map onto the ordinary concept expressed by the use of that word, what justifies calling it "belief" at all; and (ii), whether we could use an alternative terminology-e.g. that of "representation" - instead of the potentially confusing one of "belief" in the present context. To address (i), it is necessary to spell out what sort of positive claim doxastic theories might be making: since I turn to the latter point in the next section, I thereby postpone my answer until then.

As for (ii), Armstrong plausibly argues that there are not obvious and uncontroversial replacements. Since doxastic accounts of perception actually evolved into representationalist proposals by the early 1980's, it seems natural to think that the term "representation" is better suited than that of "belief" to account for perceptual experiences. Things are not so simple, though. First, if "representation" simply means environmental information conveyed to the conscious subject, it simply fulfills the same role as the notion of perceptual belief that he stipulated. Secondly, I believe that the notion of representation is easily susceptible of the same sort of criticism that Armstrong directly advances against the notion of a map: like maps,

5 More recent versions of the doxastic view construe perceptual content as propositional but nonconceptual. If anything, such approaches only highlight that doxastic accounts need not commit to a cognitively demanding view of perceptual content. Kathrin Glüer, for example, espouses a view according to which experiential beliefs ranges over what she calls phenomenal contents, that is, contents specifiable in terms of looks-locutions, where the concepts required to formulate such locutions need not be had by the subjects of the relevant experiences (cf. Glüer 2009, 2018). 
representations are things which we then use to tell how things are, whereas perceptual beliefs 'essentially refer beyond themselves to the objects they [would] claim to map' (Armstrong 1968, 210). ${ }^{6}$ And thirdly, "belief" has a methodological advantage over "representation." Expressions of belief may be applied more or less literally to an account of mental phenomena insofar as they refer to a primarily psychological notion. The idea of representation, in turn, derives from a pictorial context, not a psychological one: hence, its primary application to a story of perceptual experience will be metaphorical or analogical. The point may seem trivial, but I think that, a few notable exceptions aside (cf. Austin 1962; Hacker 1987; Snowdon 1992; Travis 2013), contemporary philosophers of perception easily slip into metaphorical or otherwise broad characterizations of perceptual phenomena when using pairs of terms like "presentation"/"representation," or, relatedly, "direct"/"indirect."

At any rate, choice of words is not the crucial point here. For present purposes, I am interested in the fact that, for doxastic theorists, the notion of belief need not serve the purpose of specifying perceptual content: as I begin explaining next, it may also throw light on the question of what kind of items perceptual attitudes are.

\section{The ontological import of perceptual attitudes: nonfactivity}

If my foregoing remarks are along the right lines, it is not compulsory to read doxastic theories as controversial stories of perceptual content. What else may such accounts spell out, then? In a nutshell, the suggestion is that the perception-belief comparison might be used not to relate perceptual content to conceptual or propositional content, but to relate perceptual attitudes to doxastic ones. In line with their ontological motivation as a reaction to sense-datum theories, a doxastic account of perceptual phenomena may deliver a story of perceptual attitudes - as opposed to perceptual contents - where, in analogy with doxastic attitudes, the relevant experiential

${ }_{6} \quad$ This succinct critical claim has, I believe, been subsequently developed in far more ambitious and sophisticated ways by Charles Travis in his more recent attacks of representationalism (cf. Travis 2013). 
attitudes are characterized by the features of stativity and nonfactivity. As previously mentioned, these considerations are not thereby intended to defend doxastic views. What I want to show is that, whether the reader take that proposal or leave it, she should appreciate the importance of philosophically describing perceptual attitudes independently of considerations regarding the intentionality or the phenomenology of perception. As I shall explain towards the end of the next section, the present characterization of perceptual attitudes has significant ontological punch to the extent that it opposes different forms of ontological reification: on the one hand, nonfactive attitudes avoid the key Phenomenological Principle underpinning a subjectivist approach to perceptual contents; and, on the other, specifying such attitudes as states avoids potentially obscuring our understanding of what perceptual experiences are made of.

To unpack the relevant ontological message, let's go back to (i), the question whether doxastic views of perception pick up on psychological attitudes that one could most suitably call "beliefs." This worry — or one quite similar to it - is voiced by Frank Jackson when objecting to the ontological significance of a belief-theory of perception vis-à-vis sense-datum theories:

One of the main aims of any belief analysis of perception is to avoid the Sense-datum theory's commitment to the existence of something $F$ when something looks $F$ to someone. The belief analysis achieves this because, despite the considerable controversy over the semantic structure of belief statements, we know enough about them to know that a statement like 'I believe (am inclined to believe) that there is something $F$ in front of me' can be true without there being anything $F$ in front of me. However, if the belief in question is not merely a common or garden one, but, rather, a special kind - a perceptual belief, where a perceptual belief is defined in terms of looking $F$ - then the whole question of ontological commitment to there being an $F$ is thrown back into the melting-pot. (Jackson 1977, 45)

As I also strived to highlight in the last section, Jackson correctly claims that the perceptual beliefs posited by the doxastic theory are not common or garden ones. But does this mean that doxastic views of perception like those of Armstrong's and Pitcher's lose the ability to counteract the 
controversial ontological commitment at the basis of the sense-datum theorist? It does not. To resist a story of perception in terms of mind-dependent items, the doxastic theorist need not assimilate the contents of perception and belief: all she has to secure is a characterization of perceptual experiences as nonfactive attitudes. ${ }^{7}$ Let's unpack this point.

To undermine the line of reasoning leading up to the introduction of sense-data, doxastic accounts challenge a key but implicit premise behind the previous understanding of illusion and hallucination: if something seems F to a subject, then something with that quality exists. This claim-nowadays known as the Phenomenal Principle (cf. Robinson 1994, 32)-relates to the feature of factivity. As traditionally understood, if a given psychological attitude towards a given content $p$ is factive, then $p$ is true whenever a given subject instantiates that attitude. Knowledge is a standard example: if you know that $2+2=4$, then it is true that $2+2=4$. According to doxastic views of perception, however, we need not commit to the Phenomenal Principle: just like beliefs, perceptual experiences might be thought to involve nonfactive attitudes - that is, attitudes where things seem a certain way even though they fail to be so. Beliefs are intuitively nonfactive in the sense that, although we always take the beliefs we endorse to be true, it does not automatically follow that their contents convey true propositions: one may believe that $p$ even when $p$ is not the case. Drawing on the comparison - and, in principle, nothing more than a comparison - between perception and belief, the doxastic theorist goes on to show that perceptual experiences may likewise constitute counter-examples to the Phenomenal Principle. Just like beliefs, experiences might be the kind of mental phenomena capable of (re)presenting things that do not exist. In other words, perceptual experiences may be conceived as phenomena that deliver accurate information - as they do in normal perception - as well as inaccurate information - as they do in perceptual illusion and hallucination - about the

7 Which does not mean that doxastic views have nothing to say about the way the sense-datum theorist understands the notion of perceptual content: their objections grounded on representational or phenomenological considerations (e.g. the discussion of the speckled hen) are well-known. My point is only that, to an important extent, such proposals are ontologically driven: they rest on a particular understanding of what sort of psychological attitude perceptual experience is. 
world. In this specific regard, perception would be like belief. And if the Phenomenal Principle thus breaks down, it is at least not obvious how reflection about the phenomena of illusion and hallucination lead up to the postulation of mind-dependent objects. The present outline is no doubt sketchy, but it highlights a key ontological motivation driving the emergence of doxastic views: they aim to describe perceptual phenomena in a way that avoids invoking controversial items like sense-data.

Even Jackson himself notes that the thrust of doxastic views against sense-datum theories does not concern the cognitive complexity of perceptual content, but the nonfactive character of perceptual experiences in general. The sense-datum theorist's mistake was to assume that, if something $\mathrm{F}$ appears to a subject, then there must be an object which instantiates $\mathrm{F}$. As far as I can see, this claim may concern the way we think about experiential attitudes rather than the cognitive complexity of experiential contents. Hence, although Jackson is certainly right in claiming that the relevant perceptual beliefs are not common or garden ones in regard to the conceptual or propositional sort of content we usually ascribe to them, the doxastic view could still make a case against sense-data by conceiving perceptual experiences as nonfactive attitudes. ${ }^{8}$ So, in spite of incorporating an idiosyncratic notion of belief into its description of perception, the doxastic view could still combat the sense-datum theory: after all, the relevant comparison with beliefs may be intended to model perceptual experiences as nonfactive, a feature that, as far I can see, need not characterize what sort of content perceptual experiences incorporate, but what kind of psychological attitudes they are.

\section{The ontological import of perceptual attitudes: stativity}

A characterization of perceptual attitudes as mental states, in turn, relates to past and recent debates about the temporal structure of perceptual

8 A possible reply consists in relating the nonfactivity of beliefs to their conceptdependence: as such, the doxastic theorist's ascription of nonfactivity to perceptual experiences would entail the conceptual character of their contents. It is unclear to me how such a suggestion could be specifically be fleshed out, though. 
experience. Claiming that either beliefs or perceptual experiences are mental states may seem inane if, as it is relatively common in current philosophy of mind, "state" is regarded as an umbrella or otherwise general term more or less exchangeable with "event," "episode," "phenomenon," etc. (cf. Byrne 2009, 432). A wider philosophical and linguistic tradition has, however, acknowledged that the difference and the relationship between all their corresponding notions are anything but trivial: for, among other things, the relevant terms are capable of codifying different ways in which items exist in time. ${ }^{9}$ I shall presently return to this point. For the time being, it is important to note that writers like Armstrong and Pitcher are well aware of the above categories and apply them to the categorization of psychological phenomena. Pitcher stresses that his account of perceptual beliefs/experiences is dispositional (cf. Pitcher 1971, 70-71), a characterization the full import of which involves at least a partial understanding of how occurrent categories (e.g. event, process) logically relate to nonoccurrent ones (e.g. state, disposition, property, etc.) (cf. Braithwaite 1932-33; Ryle 1949; Armstrong 1973; Chisholm 1957). To draw the aforementioned distinction between perceiving, perceptual experience, and perceptual beliefs, meanwhile, Armstrong explicitly relies on the categories of states, processes, and events. He spells out the latter categories as follows: a state 'endures for a greater or a lesser time, but it exists entire at each instant for which it endures;' a process 'is not entire at each instant that the process is occurring,' but 'takes time to complete, and at any instant while the process is going on a certain amount of the process has been completed while a certain amount remains to be completed;' and an event is 'the coming to be or

9 Discussions of such notions already feature in Aristotle's Physics, Metaphysics, and Nichomachean Ethics (cf. Barnes 1984; for discussion, cf. Mourelatos 1978, 1993; Gill 1993; Charles 2015, 2018). In the philosophy of mind and the philosophy of action, contributions by Ryle, Vendler, and Kenny reignited interest in the distinction between processes, events, and states (cf. Ryle 1954; Vendler 1957; Kenny 1963; Steward 1997, 2013, 2018; Soteriou 2007, 2011, 2013, 2018; Crowther 2009a, 2009b, 2010, 2011; Thompson 2008; Stout 2018). Likewise, Vendler's work triggered a massive wave of contributions in the interface between linguistics and philosophy (cf. Comrie 1976; Taylor 1977; Dowty 1979; Rothstein 2004; Galton and Mizoguchi 2009; Galton 2018). 
passing away of a state, or the initiating or terminating of a process' (Armstrong 1968, 130-31). With this framework in place, Armstrong defines perceiving as the event of acquiring information about one's own surroundings, and perceptual experience as the state of introspective awareness by means of which we keep track of the processive flow of environmental information. Although these definitions no doubt raise delicate issues - e.g. how we should precisely define the previous ontological categories, whether categorizing perception as instantaneous or near-instantaneous occurrences might lead straight up to a snapshot view of perception, or how introspection is supposed to underpin perceptual phenomena - the relevant point here is that Armstrong does not use the term "state" lightly, but is aware of its ontological import. In short, both writers seem to be sensitive to the ontological implications of characterizing perceptual attitudes along stative or dispositional lines.

As previously mentioned, the aforementioned ontological categories relate to a prominent - even if not mainstream - philosophical tradition devoted to clarify different aspects of mind in terms of their temporal structures or the ways in which the relevant aspects "fill" time. While the project of specifying the intimate but enigmatic relationship between mind and time is as old as philosophy itself, its systematic development in AngloAmerican philosophy may be traced to a rich line of work in the interface between philosophy and linguistics (cf. references in footnote 9). This literature has not only promoted a fruitful debate about how natural languages encode certain temporal distinctions: it has also provided a neat framework of ontological categories that could in principle accommodate different temporal features of mental phenomena in accordance with the ways in which we think and talk about them. Two background conditions probably played an important role configuring this pro-metaphysics landscape. First, still very much under the grip of Wittgenstein's and Ryle's works, an important number of Anglo-American philosophers did not automatically dismiss a form of conceptual analysis that bore striking structural similarities to oldschool Aristotelian ontology. ${ }^{10}$ Secondly, a lively discussion about the epistemic credentials of introspective knowledge at the time posed significant

10 For a persuasive defense of the claim that the philosophies of ordinary language championed by Moore, Ryle, and Wittgenstein, could not avoid but being covered forms of proper ontological or epistemological analysis, cf. (Ayer 1963). 
pressure on any attempt to read philosophical insights about perceptual experiences off of their respective contents. ${ }^{11}$ However, with the advent of the Australian school of psycho-physical reductionism, mainstream philosophy of mind started taking a harsher stance towards metaphysical thinking - in fact, one in line with a more general but now declining bias against metaphysics as a fully respectable subject in analytic philosophy (cf. Simons 2013) - and redirected its efforts to the development of a coherent conceptual framework for the empirical sciences of the mind. Against this backdrop, philosophical work on phenomena like perceptual experiences soon concentrated on matters of representation and intentionality.

Philosophical fashions are cyclical, though. Metaphysics has not only been making a healthy come-back as a respectable discipline on its own: its absence has also been duly noted among philosophers of mind. Only two recent examples. In line with the historical narrative outlined here, Matt Soteriou succinctly depicts the current state of philosophy of perception:

[... the focus of enquiry tends to be directed more or less exclusively on the nature of these phenomenal, what-it-is-like properties, and it is rarely made explicit how we are to think of the temporal profile of the experiences to which such properties are attributed. For example, it's not often made explicit whether the bearers of these phenomenal properties are mental events, or mental states, or mental processes. Moreover, there isn't much discussion of the relevance that these ontological considerations might have in accounting for our knowledge of what it is like to have conscious experiences. Implicit is the assumption that such matters have little to contribute to a philosophical account of sensory consciousness. (Soteriou 2013, 2)

Again, Geoffrey Lee surveys different debates concerning the temporal structure of consciousness, in order to adopt what seems to be a pro-metaphysics attitude: 'we can't hope to get the right view of the constitution of

11 A method of first-person (introspective) knowledge of perceptual experiences like that famously expressed by G.E. Moore, was critically assessed by powerful but somewhat neglected figures like George Dawes Hicks and G.A. Paul (cf. Dawes Hicks 1917; Moore 1925/1993; Paul 1936; and, for more recent discussions of that debate, also cf. Martin 2000; Snowdon 2015; Gomes 2017, 138ff.). 
the stream of consciousness without thinking carefully about the possible metaphysical forms it could have, and about the relationship it stands in to its neural realization in the brain' (Lee 2014, 19). The background thought is, I believe, that what one might call an attitude of ontological indifference underpins contemporary debates about the stream of consciousness. Indeed, such an attitude has widely dominated and impoverished discussions about the intentional and the phenomenological character of perceptual experiences.

At the same time as a renewed interest in the ontological structure of mental phenomena gains strength, doubts concerning our alleged introspective access to the contents of experience progressively build up. Over the past three decades, the two main accounts of perception-viz. representationalism and relationalism - have clashed on which proposal best accommodates the intentional or the phenomenological character of perceptual experience, as unveiled by introspective awareness. Of course, this dialectic assumed that introspection provides a relatively reliable picture of what our senses (re)present to us and of their corresponding phenomenology. However, just as G.E. Moore's first-person method of introspective inquiry met a significant amount of pressure, claims about the introspective transparency of experience that only a few years ago drove the philosophical debate, are now the object of serious scrutiny (cf. Spener 2012; Zimmerman 2012).

Given the previous conditions, it is thereby no coincidence that philosophers of perception are coming to realize that a study of perceptual content will not on its own carve perceptual experiences at their joints. Correspondingly, a stimulating debate over the temporal structure of perceptual experience - as a discussion over and above one about temporal content-has been taking shape. In what is quickly becoming the philosophical orthodoxy, a number of writers have suggested that perceptual experience has to be conceived in terms of phenomenally conscious processes, the parts of which are not as it were reducible to objects, properties, relations, or states conceived as instantiations of properties/relations: according to this proposal, perceptual experiences involve processes that are constituted by further processes down to their infinitesimal or quasi-infinitesimal parts (cf. O'Shaughnessy 2000, Ch. 1; Soteriou 2007, 2011, 2013). To the extent that they conceive experiences in terms of necessarily processive or dynamic 
items, these accounts may be characterized as a restricted form of Heracliteanism. Experiential Heracliteanism is often driven by phenomenological motivations - in broad lines, the thought being that certain features of the temporal phenomenology of experience (e.g. temporal transparency, experience's stream-like or continuous character, etc.) are best accommodated by an ontology of necessarily or irreducibly dynamic processes. Non-Heraclitean approaches may, by contrast, concede the phenomenological data, but deny that it is therefore necessary to espouse an experiential ontology involving irreducible change. ${ }^{12}$ By characterizing perceptual attitudes in terms of nonfactive states rather than irreducible processes, doxastic views of perception seem to go non-Heraclitean. This whole ontological debate is naturally far too complex and delicate to be dealt with here. For present purposes, the foregoing remarks only aim to give the reader a taste of how a characterization of perceptual attitudes in terms of temporal or otherwise ontological categories like states and processes fits into an important tradition in the philosophy of mind.

As previously mentioned, I believe that a characterization of perceptual attitudes as nonfactive and stative avoids different ways of reifying perceptual experiences. Bearing the content-attitude distinction in mind, an ontology of experiential contents as well as one of experiential attitudes may invoke dubious entities. For example, accounts that resorted to sense-data and other forms of qualitative entities tended to reify the contents of experience. Something like Experiential Heracliteanism, in turn, models perceptual attitudes in terms of necessarily dynamic processes: to the extent that physical and psychological but nonconscious processes are generally taken to involve properties, relations, or the instantiation thereof, the introduction of irreducibly processive items into our understanding of conscious reality constitutes a serious and controversial ontological commitment. In

12 Experiential non-Heracliteanism need not go Parmenidian, that is, it need not deny that experiences are dynamic phenomena. Heracliteanism and non-Heracliteanism may share that thought: they would specifically clash with each other on the question whether such dynamic phenomena should be accounted for in terms of dynamic or non-dynamic components. The dialectic is thereby structurally similar to that between dynamic and static theories of time or that between dynamic and static theories of experienced temporal passage. 
short, the notion of necessarily dynamic conscious processes seems to reify perceptual phenomena on the attitude-side the same way that sense-data reified them on the content-side. A characterization of perceptual attitudes as nonfactive states could avoid either threat: on the one hand, the Phenomenal Principle need not force it to posit items we could be aware of in veridical as well as hallucinatory experiences; and, on the other, that characterization could afford describing the conscious and the nonconscious world in similar ontological terms.

To sum up. I have examined doxastic views of perception in order to unveil ontological - as opposed to purely intentional or phenomenologicalmotivations driving a description of perceptual attitudes. While this dimension seems to be reemerging in a new wave of literature about perception, it probably passed unnoticed among philosophers who, like Evans, primarily strived to individuate perceptual experiences in terms of their contents. By setting the historical record straight, I have not thereby intended to espouse a doxastic view of perception, but to highlight a line of ontological thinking that could enrich traditional debates about the intentionality and the phenomenology of perception.

\section{Conclusion}

Classic doxastic accounts of perception like those of Armstrong's and Pitcher's do not seem to have the counterintuitive consequence Evans accused them of, and I think it is philosophically instructive to examine why this is so. The objection from over-intellectualization would affect them only had they aimed to model perceptual content along the lines of the far more cognitively sophisticated contents of our garden beliefs. However, if a reading along the lines sketched here is sound, that is not what they aimed for: a doxastic stance primarily compares perception and belief in order to develop a particular story of perceptual attitudes - more specifically, one of perceptual attitudes as nonfactive states. Pace Jackson, such a characterization would not be ontologically irrelevant: for, on the one hand, the notion of nonfactivity plays a crucial role against the infamous Phenomenal Principle; and, on the other, a stative conception of perceptual attitudes bears on past as well as recent discussions about the temporal structure of 
experience. To stress this point once more: my intended conclusion is not that we should endorse a doxastic view of perception; but, instead, that recent and current philosophical theories of perception should not be framed and assessed only in terms of intuitions about the intentionality and the phenomenology of perception, but also in terms of independent claims about its ontological structure.

I have chosen to ground the present discussion on the controversy between Evans's objection and classic doxastic views of perception because that debate as it were epitomizes a paramount crossroads in Twentieth Century's philosophy of perception. Armstrong and Pitcher belong to a philosophical tradition that includes the works of writers like Moore, Wittgenstein, Ryle, Vendler, among other Oxbridge figures - in short, philosophers with a keen interest in the ontological or otherwise conceptual structure of mental phenomena in general. Evans, in turn, represents a fashion of empirically informed philosophy of mind that systematically avoided old-school metaphysics - much of this attitude influenced by the work of Quine, Sellars, Dennett, and to some extent Davidson - so as to focus on a systematic analysis of mental content and its related phenomenology. Hence, both sides of the previous controversy apparently represent two traditions that unfortunately talked past each other, a misunderstanding of a general sort that current philosophers of mind are slowly coming to appreciate and rectify. Fortunately for us, we do not have to choose: to understand perceptual experiences, philosophers of mind may benefit from inquiring into the nature of perceptual contents as well as that of perceptual attitudes. To conclude, I shall briefly comment on possible cross-overs.

Throughout this piece, I have repeatedly mentioned that the present discussion should not be understood as a defense of doxastic views. To illustrate this claim, note that a non-doxastic form of representationalism also accommodates a characterization of perceptual attitudes as nonfactive states (cf. Tye 1995; Pautz 2010; Siegel 2011). As to the question which specific account of experience we should thereby endorse, this piece remains completely silent. For present purposes, however, it is important to bear in mind that the representationalist rejection of the Phenomenal Principleand, hence, of sense-datum theories - is usually grounded on considerations from perceptual phenomenology, introspective transparency, and objective 
thought. And while such considerations are for sure philosophically relevant, my general point is that the same account of experience could also be framed or motivated by thinking what kind of items perceptual attitudes are.

Again, Matt Soteriou has recently engaged in an ambitious project of relating the traditional representationalism-relationalism debate to the aforementioned discussion between Heraclitean and non-Heraclitean views of experience. After binding relationalism to Heracliteanism and representationalism to non-Heracliteanism, he strives to drive a wedge between both pairs of views. In broad lines, then, his objective is to show how considerations about the ontological structure of experience bear on a defense of the relationalist view of perception he seeks to endorse. Soteriou's individual arguments are profound and his emphasis on ontological issues heavily influences this piece, but I believe - a point I can only voice here - that the links he draws between both pairs of account deserve further attention. For example, his critique of a non-Heraclitean account of perceptual experiences heavily draws on considerations about representationalism's alleged failure to accommodate the phenomenology of temporal passage. According to this line of reasoning, non-Heracliteanism and representationalism stand or fall together. But while Soteriou goes to some lengths to show that the representationalist has to go non-Heraclitean, he does little to show that Experiential non-Heracliteanism necessarily involves a representationalist view of experience. As far as I can see, the relationship between the ontology and the phenomenal/intentional character of perception is looser than Soteriou wants to make it seem. If states are conceived as instantiations of properties or relations, for example, it is then tempting to depict perceptual states along relationalist lines. Such a characterization would not, however, rely on claims about the ways in which we think or are introspectively aware of an objective world conveyed by the senses: it is motivated by considerations regarding what kind of items our perceptual experiences are.

\section{Acknowledgments}

Because of its many flaws, this piece has been many years in the making. Back in 2015, it benefited from the feedback provided by the audience attending the "Philosophy of Mind: Ontology, Consciousness, Attention" workshop at the Pontifical 
Catholic University of Chile (Santiago, Chile). For helpful comments on previous iterations, I am especially indebted to José Tomás Alvarado, Tim Bayne, Alex Geddes, Boris Lucero, José Luis Liñán, Francisco Pereira, Chiara Saracini, Paul Snowdon, Zoltan Istvan Zardai, and an anonymous reader at this journal.

\section{Funding}

This article was partially developed with the generous support of the FONDECYT Postdoctoral Fellowship No. 3160082.

\section{References}

Armstrong, David Malet. 1968. A Materialist Theory of the Mind. London:

Routledge. https://doi.org/10.4324/9780203003237

Armstrong, David Malet. 1973. Belief, Truth, and Knowledge. Cambridge: Cam-

bridge University Press. https://doi.org/10.1017/CBO9780511570827

Austin, John. 1962. Sense and Sensibilia. Oxford: Clarendon Press.

Ayer, Alfred. 1963. "Philosophy and Language." In The Concept of a Person, 1-

35. New York: St Martin's Press.

Barnes, Jonathan. 1984. Complete Works of Aristotle, Volume 1: The Revised Oxford Translation. Princeton: Princeton University Press.

Braithwaite, R. B. n.d. "The Nature of Believing." Proceedings of the Aristotelian Society 33: 129-46. https://doi.org/10.1093/aristotelian/33.1.129

Byrne, Alex. 2009. "Experience and Content." The Philosophical Quarterly 59:

429-51. https://doi.org/10.1002/9781444343915.ch4

Chisholm, Roderick M. 1957. Perceiving: A Philosophical Study. Ithaca, NY: Cornell University Press.

Comrie, Bernard. 1976. Aspect. Cambridge: Cambridge University Press.

Craig, Edward. 1976. "Sensory Experience and the Foundations of Knowledge."

Synthese 33 (1): 1-24. http://www.jstor.org/stable/20115122

Crane, Tim. 2001. Elements of Mind: An Introduction to the Philosophy of Mind. Oxford University Press. https://global.oup.com/ushe/product/elements-ofmind-9780192892973?cc=cl\&lang $=$ en\&

Crowther, Thomas. 2009a. "Perceptual Activity and the Will." In Mental Actions, edited by Lucy O'Brien and Matthew Soteriou, 173-90. Oxford: Oxford University Press. http://doi.org/10.1093/acprof:oso/9780199225989.003.0009

Crowther, Thomas. 2009b. "Watching, Sight, and the Temporal Shape of Perceptual Activity." The Philosophical Review 118 (1): 1-27.

https://doi.org/10.1215/00318108-2008-027

Organon F 27 (1) 2020: 2-28 
Crowther, Thomas. 2010. "The Agential Profile of Perceptual Experience." In Proceedings of the Aristotelian Society, 110:219-42.

https://doi.org/10.1111/j.1467-9264.2010.00285.x

Crowther, Thomas. 2011. "The Matter of Events." The Review of Metaphysics 65 (1): 3-39.

Dawes Hicks, George. 1917. "Are the Materials of Sense Affections of the Mind?" Proceedings of the Aristotelian Society 17 (1): 418-58.

https://doi.org/10.1093/aristotelian/17.1.418

Dowty, David. 1979. Word Meaning and Montague Grammar. Dordrecht: Reidel Publishing Co. https://doi.org/10.1007/978-94-009-9473-7

Evans, Gareth. 1982. The Varieties of Reference. Oxford: Clarendon Press.

Glüer, Kathrin. 2009. "In Defence of a Doxastic Account of Experience." Mind \& Language 24 (3): 297-327. https://doi.org/10.1111/j.1468-0017.2009.01364.x

Glüer, Kathrin. 2018. "Defeating Looks." Synthese 195 (7): 2985-3012. https://doi.org/10.1007/s11229-016-1186-x

Gomes, Anil. 2017. "Perception and Reflection." Philosophical Perspectives 31: 131-52. https://doi.org/10.1111/phpe.12093

Hacker, Peter Michael Stephan. 1987. Appearance and Reality: A Philosophical Investigation into Perception and Perceptual Qualities. Oxford: Basil Blackwell.

Heck Jr, Richard G. 2000. "Nonconceptual Content and the 'Space of Reasons." The Philosophical Review 109 (4): 483-523. http://doi.org/10.2307/2693622

Heil, John. 1984. Perception and Cognition. Berkeley: University of California Press.

Jackson, Frank. 1977. Perception: A Representative Theory. Cambridge: Cambridge University Press.

Kenny, Anthony. 1963. Action, Emotion and Will. London: Routledge \& Kegan Paul.

Lee, Geoffrey. 2014. "Temporal Experience and the Temporal Structure of Experience." Philosophers' Imprint 14 (3): 1-21. http://hdl.handle.net/2027/spo.3521354.0014.003

Martin, M. G. F. 2000. "Beyond Dispute: Sense-Data, Intentionality and the MindBody Problem." In History of the Mind-Body Problem, edited by Tim Crane and Sarah Patterson, 195-231. London: Routledge.

Martin, Michael G.F. 2002. "The Transparency of Experience." Mind and Language 17: 376-425. https://doi.org/10.1111/1468-0017.00205

McDowell, John. 1994. Mind and World. Cambridge, MA: Harvard University Press.

Moore, G.E. n.d. "A Defense of Common Sense." In G.E. Moore: Selected Writings, edited by Thomas Baldwin, 106-33. London: Routledge. 
O'Shaughnessy, Brian. 2000. Consciousness and the World. Oxford: Oxford University Press. http://doi.org/10.1093/0199256721.001.0001

Paul, G.A. 1936. "Is There a Problem about Sense-Data?" Proceedings of the Aristotelian Society 15: 61-101. https://doi.org/10.1093/aristoteliansupp/15.1.61

Pautz, Adam. 2010. "Why Explain Visual Experience in Terms of Content?" In Perceiving the World, edited by Bence Nanay, 254-309. Oxford: Oxford University Press. http://doi.org/10.1093/acprof:oso/9780195386196.003.0010

Pitcher, George. 1971. A Theory of Perception. Princeton: Princeton University Press.

Robinson, Howard. 1994. Perception. London: Routledge.

Rothstein, Susan. 2004. Structuring Events: A Study in the Semantics of Lexical Aspect. Malden, MA: Blackwell. http://doi.org/10.1002/9780470759127

Roxbee Cox, J.W. 1971. "An Analysis of Perceiving in Terms of the Causation of Beliefs." In Perception: A Philosophical Symposium., edited by Frank Sibley, 23-62. London: Methuen.

Ryle, G. 1949. The Concept of Mind. London: Hutchinson.

Ryle, Gilbert. 1954. Dilemmas. Cambridge: Cambridge University Press. https://doi.org/10.1017/CBO9781316286586

Sibley, Frank. 1971. "Analysing Seeing." In Perception: A Philosophical Symposium., edited by Frank Sibley, 81-132. London: Methuen.

Siegel, Susanna. 2011. The Contents of Visual Experience. Oxford: Oxford University Press. http://doi.org/10.1093/acprof:oso/9780195305296.001.0001

Simons, Peter. 2013. "Metaphysics in Analytic Philosophy." In The Oxford Handbook of the History of Analytic Philosophy, edited by Michael Beaney, 709-28. Oxford: Oxford University Press. http://doi.org/10.1093/oxfordhb/9780199238842.013.0015

Smith, Peter, and Owen Rogers Jones. 1986. The Philosophy of Mind: An Introduction. Cambridge: Cambridge University Press.

https://doi.org/10.1017/CBO9780511621208

Snowdon, Paul. 1992. "How to Interpret 'Direct Perception.'" In The Contents of Experience, edited by Tim Crane, 48-78. Cambridge: Cambridge University Press. https://doi.org/10.1017/CBO9780511554582.004

Snowdon, Paul. 2015. "Sense-Data." In The Oxford Handbook of Philosophy of Perception, edited by Mohan Matthen, 118-35. Oxford: Oxford University Press. http://doi.org/10.1093/oxfordhb/9780199600472.013.021

Soteriou, Matthew. 2007. "Content and the Stream of Consciousness." Philosophical Perspectives 21 (1): 543-68. https://doi.org/10.1111/j.15208583.2007.00135.x

Soteriou, Matthew. 2011. "Occurrent Perceptual Knowledge." Philosophical Issues 21 (1): 485-504. https://doi.org/10.1111/j.1533-6077.2011.00213.x 
Soteriou, Matthew. 2013. The Mind's Construction: The Ontology of Mind and Mental Action. Oxford: Oxford University Press. http://doi.org/10.1093/acprof:oso/9780199678457.001.0001

Soteriou, Matthew. 2018. "Experience, Process, Continuity, and Boundary." In Process, Action, and Experience, edited by Rowland Stout, 82-101. Oxford: Oxford University Press. http://doi.org/10.1093/oso/9780198777991.003.0005 Spener, Maja. 2012. "Mind-Independence and Visual Phenomenology." In Introspection and Consciousness, edited by Declan Smithies and Daniel Stoljar, 381-404. Oxford: Oxford University Press. http://doi.org/10.1093/acprof:oso/9780199744794.003.0014

Steward, Helen. 1997. The Ontology of Mind: Events, Processes, and States. Oxford: Clarendon Press. http://doi.org/10.1093/acprof:oso/9780198250647.001.0001

Steward, Helen. 2013. "Processes, Continuants, and Individuals." Mind 122: 781812. https://doi.org/10.1093/mind/fzt080

Steward, Helen. 2018. "Occurrent States." In Process, Action, and Experience, edited by Rowland Stout, 102-19. Oxford: Oxford University Press. https://doi.org/10.1093/oso/9780198777991.003.0006

Taylor, Barry. 1977. "Tense and Continuity." Linguistics and Philosophy 1: 199220. https://doi.org/10.1007/BF00351103

Thompson, Michael. 2008. Life and Action. Cambridge, MA: Harvard University Press. http://doi.org/10.4159/9780674033962

Travis, Charles. 2013. Perception: Essays after Frege. Oxford: Oxford University Press. http://doi.org/10.1093/acprof:oso/9780199676545.001.0001

Tye, Michael. 1995. Ten Problems of Consciousness: A Representational Theory of the Phenomenal Mind. Cambridge, MA: The MIT Press.

Vendler, Zeno. 1957. "Verbs and Times." The Philosophical Review 66: 143-60. https://doi.org/10.2307/2182371

Zimmerman, Aaron. 2012. "Introspection, Explanation, and Perceptual Experience: Resisting Metaphysical Disjunctivism." In Introspection and Consciousness, edited by Declan Smithies and Daniel Stoljar, 353-80. Oxford: Oxford University Press. http://doi.org/10.1093/acprof:oso/9780199744794.003.0013 